$2020,21(1)$, pp. 114 - 127, DOI: 10.18038 /estubtda. 712003

\title{
SYNERGISTIC EFFECT OF POLYMER-POLYMER MIXTURES AS DRAG REDUCING AGENTS ON OIL-WATER FLOWS
}

\author{
Lawrence Chukwuka Edomwonyi-Otu ${ }^{1,2}$, Muhammad Muhammad Gimba ${ }^{2}$, \\ Yusuf Nurudeen ${ }^{3}$, Abdulkareem Abubakar ${ }^{2}$ \\ ${ }^{1}$ Department of Chemical and Petroleum Engineering, Delta State University, Abraka, Nigeria. 334101 \\ ${ }^{2}$ Department Chemical Engineering, Ahmadu Bello University, Zaria, Nigeria. 810221 \\ ${ }^{3}$ Department of Chemical and Petroleum Engineering, Bayero University, Kano, Nigeria. 700241
}

\begin{abstract}
The synergistic effect of natural and synthetic polymers as drag reducing agents in water phase during horizontal oil-water flows was studied in $12 \mathrm{~mm}$ internal diameter (ID) unplasticised polyvinylchloride (UPVC) pipe. Partially hydrolyzed polyacrylamide (HPAM; trade name as magnafloc 1011 or Separan), polyethylene oxide (PEO; trade name as Polyox WSR 310), Aloe Vera mucilage (AVM; as Aloe barbadensis miller), mixture of partially hydrolyzed polyacrylamide and Aloe Vera mucilage and polyethylene oxide and Aloe Vera mucilage (HPAM-AVM and PEO-AVM) were used. Mixture Reynolds number of 62923, master solution of $2000 \mathrm{ppm}$ and $20000 \mathrm{ppm}$, and total concentration (TC) of $30 \mathrm{ppm}$ and $400 \mathrm{ppm}$ were investigated using diesel oil $(\rho=832 \mathrm{~kg} / \mathrm{m} 3, \mu=1.66 \mathrm{cP})$ and water $(\rho=1000 \mathrm{~kg} / \mathrm{m} 3, \mu=0.89 \mathrm{cP})$ as test fluids. The results show that the drag reduction (DR) of 65.39 and $69.23 \%$, and 69.23 and $70.77 \%$ were obtained for HPAM-AVM and PEOAVM mixtures respectively, at mixing ratios of $3: 1$ and $1: 19$, for $25 \%$ oil input fraction and water phase Reynolds number (Rew) of 47192. These values were found to be higher than the DR obtained by individual polymer alone at the same conditions. Drag reduction decreased with increase in the oil input fraction due to the decrease in the water phase Reynolds number. The result implies drag reduction efficiency can be enhanced by combining natural and synthetic polymers.
\end{abstract}

Keywords: Drag reduction, Synergism, Polymers, Polymer-polymer mixture, Oil-water flow

\section{INTRODUCTION}

Pressure drop is usually encountered during transportation of oil-water in a pipeline in process and petroleum industries due to an increase in drag force. High power consumption (pumping energy) is required to overcome the drag force. This involves installation of many pumping systems, which will increase the cost of production [1-3]. The addition of minute amount of additive known as drag reducing agents (DRA) such as polymers, surfactants, fibers or their mixtures to reduce frictional pressure drop in pipelines. This reduction in pressure drop and saving of pumping requirement by DRA is referred to as drag reduction $[4,5,6-9]$.

Most successful application of drag reduction (DR) is the use of polymers to enhance the crude oil transport through Trans-Alaska pipeline system (TAPS) completed in 1979 where $1 \mathrm{ppm}$ of drag reducer increased the flow rate by 33 percent. Others crucial pipelines drag reduction are; Turkey-Iraq, Bombay off shore India, Bas Strait Australia, etc [10, 11]. In addition, marine and biomedical system, irrigation, floodwater disposal and sewage, drilling of oil from reservoir, firefighting, extraction, filtration, heat and mass transfer application were among other applications[3, 12]. It is also now being suggested for transportation of drinking water because of its harmless properties [13].

Some drag reducing polysaccharides such as Aloe Vera mucilage (AVM) are natural drag reducing agents, less efficient on drag reduction, biodegradable and environmental friendly $[14,15]$. Polyethylene oxide (PEO) and partially hydrolyzed polyacrylamide (HPAM) are very efficient in DR and less environmentally friendly due to their high resistance to biodegradation [16]. However, the major characteristics in pipeline oil-water flow are pressure drop, flow pattern and holdup. Pressure drop in

*Corresponding Author uceclce@ucl.ac.uk

Received: 02.10.2018 Published: 31.03.2020 
oil-water flow can be influence by Reynolds number (Re), temperature and pressure. Though, the Re depends on superficial or mixture velocity, pipe diameter,density, viscosity, each phase volume fraction, pressure and temperature. All the above listed parameters affect pressure drop in fluid flow $[5,17]$. The effect of a mixture of flexible (synthetic) and rigid (natural) drag reducing polymers on pressure drop is the main focus of this study. Many works have done on pressure drop reduction in oil-water flows. AlWahaibi et al.[18] were the first to report a documented work on DR in liquid-liquid flows. They investigated the effect of two concentrations $(20$ and $50 \mathrm{ppm})$ of a co-polymer of polyacrylamide and sodium acrylate (trade name as Magnafloc 1011) in $14 \mathrm{~mm}$ ID horizontal acrylic pipe on oil-water flows. They achieved maximum DR of 50\%. They also observed that pressure drop decrease with increased in the water phase velocity which is similar with the findings of Al-Yaari et al.[19]. Al-Yaari et al.[19] used three different molecular weights PEO of concentration ranging from $10-15 \mathrm{ppm}$ in $25.5 \mathrm{~mm}$ ID horizontal pipe and using kerosene as the oil phase. They reported that pressure drop is a function of water fraction, mixture velocity, concentration and molecular weight of the drag reducing polymer and drag reduction effectiveness (DRE) decreased in the presences of salt water. Omer and Pal[20] also used two different molecular weight PEO and Carboxymethyl cellulose in different horizontal pipe ID. They observed negative effect on pressure drop due to the insolubility of the drag reducing polymers in the oil phase. Yusuf et al.[21] studied the effect of drag reducing polymer on pressure drop using acrylamide co-polymer (trade name as Magnafloc 1035) with concentration ranging from 2-10 ppm in a horizontal pipe diameter of $25.4 \mathrm{~mm}$ ID and length of $8 \mathrm{~m}$ using high viscous oil (mineral oil). A maximum DR of $60 \%$ was achieved. Langsholt[22] used both water and oil soluble polymers at mixture velocity of $1.5 \mathrm{~m} / \mathrm{s}$. It was reported that DR in oil-water flows increased with increase in input volume fraction of the drag reducing polymer soluble phase. Al-Wahaibi et al.[2] studied effect of pipe diameter (19 $\mathrm{mm}$ and $25.4 \mathrm{~mm}$ ) on DR in horizontal oil-water flows. DR of $60 \%$ in $25.4 \mathrm{~mm}$ and $45 \%$ in 19 mm ID pipe was achieved. Edomwonyi-Otu and Angeli[3] investigated on effect of polymer addition on pressure drop and interfacial waves in horizontal oil-water flows using polyacrylamide of Magnafloc 1011 in $14 \mathrm{~mm}$ ID acrylic pipe with middle distillate as oil phase. They reported that mixture velocity affected pressure drop in oil-water flows and small amount of DRP reduces drag for both single and multiphase flow. Abubakar et al. [1] also studied drag reduction with polymer in oilwater flow in relative large pipe diameter using co-polymer of polyacrylamide and 2-acryamido-2methylpropane Sulphonic acid (trade name as AN 105-SH) in $74.7 \mathrm{~mm}$ horizontal pipe and length of $12 \mathrm{~m}$. They also reported that DR decreased with increase in oil input volume fraction but increased with increase in mixture velocity.

In spite of the works done in understanding the interaction between natural and synthetic polymer solutions in pipeline oil-water flows, the literature is still scanty compared to synthetic polymers. In addition, more data is needed to develop models for the accurate prediction of drag reduction in binary system. Thus, the aim of this work is to provide more data on the study of the synergistic effect of aloe Vera mucilage (AVM), polyethylene oxide (PEO) and partially hydrolyzed polyacrylamide (HPAM) in a horizontal oil-water flow system.

\section{MATERIALS AND METHODS}

\subsection{The Flow Facility}

The schematic diagram of the experimental set-up is shown in Figure 1. The flow facility is divided into three sections which are: the handling section, pumping or regulating section and test section. The handling section consists of three tanks where the fluids are stored: the oil, water and separator tanks have capacity of 200, 200 and 220 liters respectively. The separator tank allows settling under gravity where water is drain through the bottom opening and the oil is recycled. In the regulating or pumping section, $12 \mathrm{~mm}$ ID unplasticised polyvinylchloride (uPVC) pipes are each connected to the water and oil tanks. The centrifugal pumps (model Jet 102M/N.31227) with maximum flow rate of $65 \mathrm{l} / \mathrm{min}$ each were used to circulate the test fluids into the test section. The globe valves were used to regulate the flow rates which were measured with variable area flow meters (LZM-20J; $\pm 2 \%$ accuracy), separate for each fluid. The water flow meter has a maximum flow rate of 24 GPM or 100 LPM. The flow meters 
were calibrated before the commencement of experiments. The injection port for the polymer master solution is located by the side of the water pipeline before the Y-junction. The new Era-programmable peristaltic injection pump (model NE-9000; $\pm 2 \%$ accuracy) was used to inject the polymer master solution into the water phase. The test section was made up of straight acrylic pipe of $12 \mathrm{~mm}$ ID and 140 times the diameter of the pipe (140D) long from the Y-junction to the second pressure port. The pressure taps were created by making small holes at the bottom of the acrylic pipe walls at the distance of 140D which provides fully developed flow in the test section.

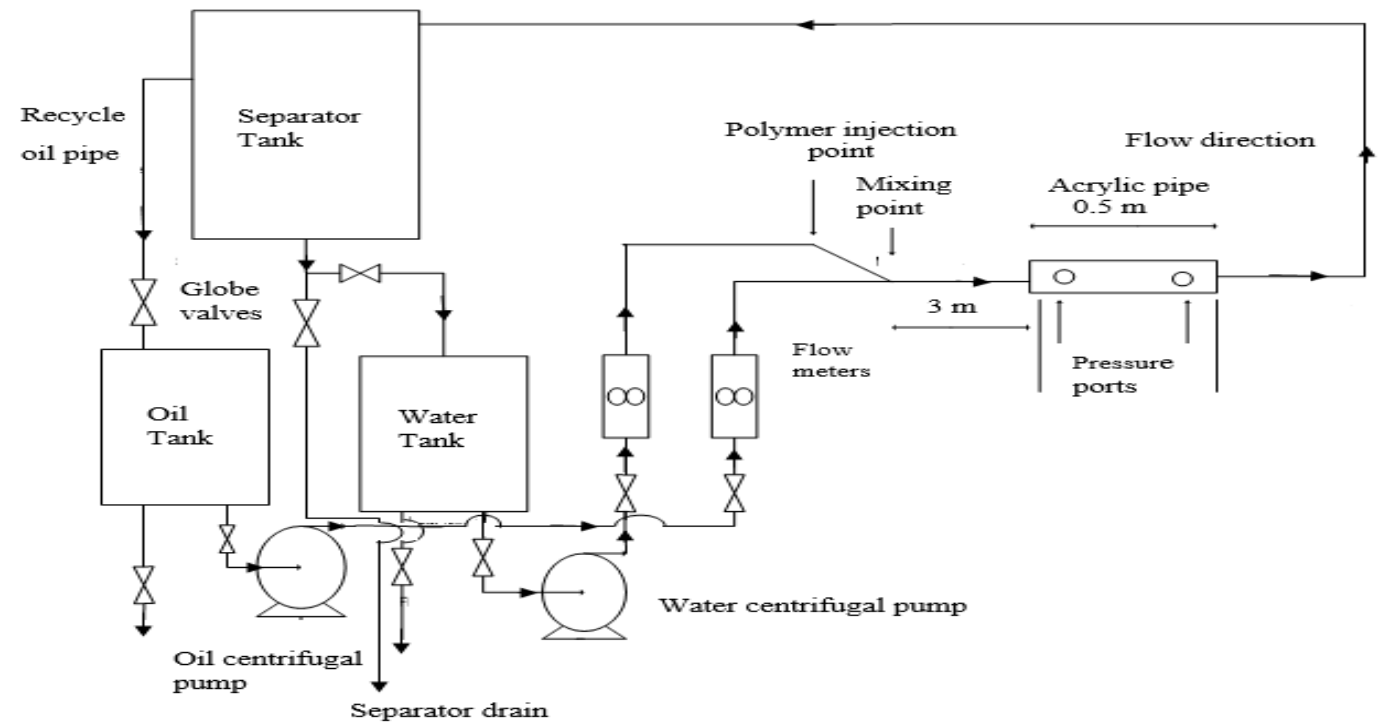

Figure 1: Schematics of experimental set-up

\subsection{Polymer Preparation}

The polymers used were partially hydrolysed polyacrylamide, (HPAM; trade name as magnafloc 1011 or Separan) manufacture by BASF chemicals with average molecular weight of $10 \times 10^{6} \mathrm{~g} / \mathrm{mol}$, polyethylene oxide (PEO; trade name as Polyox WSR 310) manufacture by Sigma-Aldrich with average molecular weight of $8 \times 10^{6} \mathrm{~g} / \mathrm{mol}$ and Aloe Vera mucilage (AVM) extracted from Aloe Vera plant. All the polymers are water soluble and were used without further purification. The polymers solutions were prepared individually first, before the polymer mixture solutions were prepared. A master solution of $2000 \mathrm{ppm}$ of each of the synthetic polymer was prepared as follows. $10 \mathrm{~g}$ of each of the polymer powder was measured using weighing balance (Kerro, BLC 3002) and gently spread over 5 liters of water surface and stirred for 3 hours with a mechanical stirrer (Gilverson, L28) at a very low speed (to avoid degradation of the polymer) for the mixture to be completely homogenized. The stirred solution was left for 12 hours overnight to ensure complete dissolution of the polymer particles and removal of trapped gas bubbles to form the master solution [23, 24]. Aloe Vera leaves were harvested from a garden in Zaria and identified at an herbarium as Aloe barbadensis miller and then washed thoroughly. The Aloin within the leaves were removed by cutting and soaking in water for about 10 minutes. After peeling, the Aloe Vera mucilage (AVM) was extracted by scraping and sieving the gel from the leaves [25], which contains about $98 \%$ water while the remaining $2 \%$ is the AVM [26, 27]. This implies that Aloe Vera leaf contains $20,000 \mathrm{ppm}$ of the AVM by volume. Table 1 gives the main compounds in Aloe barbadensis mill molecular weight in $\mathrm{g} / \mathrm{mol}[26,27]$.

Table 1. Compound in Aloe barbadensis mill molecular weight

\begin{tabular}{ll}
\hline Compound & Molecular weight $(\mathrm{g} / \mathrm{mol})$
\end{tabular}


Edomwonyi-Otu et al. / Eskişehir Technical Univ. J. of Sci. and Tech. A - Appl. Sci. and Eng. 21 (1) - 2020

\begin{tabular}{ll}
\hline Aloeride & $4 \times 10^{6}$ \\
Acemannan & $1 \times 10^{6}$ \\
50/50 Glucose-Mannose & $4.2 \times 10^{5}$ \\
Polyuronide & $2.75 \times 10^{5}$ \\
Aloeferon & $7.0 \times 10^{4}$ \\
Verectin & $2.9 \times 10^{4}$ \\
Arabinogalactan & $4 \times 10^{5}$ \\
\hline
\end{tabular}

AVM get degraded within 24 hours of the preparation [16, 25]. For the polymer mixture preparation, The total concentration (TC) of $30 \mathrm{ppm}$ and $400 \mathrm{ppm}$ for the mixture (HPAM-AVM and PEO-AVM) were chosen based on the fact that at least one of the polymers in the mixture gave maximum DR at that concentration [28].1 liter of 20,000 ppm of AVM master solution was diluted with 5.4 liter of water to achieved $500 \mathrm{ppm} .1500 \mathrm{ppm}$ of the synthetic polymers (HPAM \& PEO) was mixed with $500 \mathrm{ppm}$ of AVM and stirred for 3 hours and left to form a master solution of $2000 \mathrm{ppm}$ for the polymer mixtures [29, 28]. It was added to the water line at specific flow rate depending on the desired in-situ concentration.

\subsection{Experimental procedure}

The flow meters and injection pump were tested before running the experiments to ensure accurate delivery of the required amounts of oil and water into the test section, and the polymer master solution into the water phase. The experiment was carried out in horizontal pipe diameter of $12 \mathrm{~mm}$ ID and length of $140 \mathrm{D}$ at ambient conditions $\left(25^{\circ} \mathrm{C}, 1 \mathrm{~atm}\right)$. The U-tube manometer (Pyrex) was used for the pressure drop measurement. Each experimental run was repeated three times and the average of the pressure drop measured before and after the addition of the DRAs. HPAM, PEO, AVM, HPAM-AVM and PEO-AVM were tested at different oil input volume fraction $\left(\delta_{\mathrm{o}}\right)$ and mixture Reynolds number (Mix-Re). The total concentration (TC) of $30 \mathrm{ppm}$ and $400 \mathrm{ppm}$ for HPAM, PEO, Aloe Vera mucilage (AVM) as well as their mixtures at flow rate of $30 \mathrm{1} / \mathrm{min}$ (Re of 62923) were tasted. The Mix-Re was obtained from the summation of the Reynolds number of the water $\left(\operatorname{Re}_{\mathrm{w}}\right)$ and that of the oil phase $\left(\operatorname{Re}_{\mathrm{o}}\right)$, at different mixture and superficial velocities of water (Usw) and oil (Uso). The total concentration (TC) of $30 \mathrm{ppm}$ and 400 ppm for the polymer mixtures (HPAM-AVM and PEO-AVM) at Reynolds number of 62923 were tested. The various proportion of the oil input volume fractions were $0,25,50,75$ and $100 \%$. The pressure drop was recorded and used for calculation of drag reduction, define by the given Equation 1:

$$
D R=\frac{\Delta P_{W O}-\Delta P_{W}}{\Delta P_{W O}} \times 100 \%
$$

where; $\Delta P_{W O}$ and $\Delta P_{W}$ is pressure drop of the fluid without and with DRAs.

Table 2. Fluid properties

\begin{tabular}{ll}
\hline Properties & Values \\
\hline Density of water, $\rho_{w}$ at $25^{\circ} \mathrm{C}$ & $1000 \mathrm{~kg} / \mathrm{m}^{3}$ \\
Density of diesel oil, $\rho_{o}$ at $25^{\circ} \mathrm{C}$ & $832 \mathrm{~kg} / \mathrm{m}^{3}$ \\
Viscosity of water, $\mu_{w}$ at $25^{\circ} \mathrm{C}$ & $8.9 \times 10^{-4} \mathrm{Ns} / \mathrm{m}^{2}$ \\
Viscosity of water oil, $\mu_{o}$ at $25^{\circ} \mathrm{C}$ & $1.664 \times 10^{-3} \mathrm{Ns} / \mathrm{m}^{2}$ \\
\hline
\end{tabular}

\section{RESULTS AND DISCUSSION}

\subsection{Single Phase Experiments}

Figure 2 show the preliminary results of the drag reduction of HPAM, PEO, AVM, HPAM-AVM and PEO-AVM in single phase water flow at different concentrations and Reynolds numbers ranging from $21519,42229,62923$ and 81424 . The mixing ratio of 3:1 and 1:19 was chosen due the fact that, maximum DR was achieved at that mixing proportion. The optimal concentration of $30 \mathrm{ppm}, 400 \mathrm{ppm}$, 
$22.5 \mathrm{ppm}-7.5 \mathrm{ppm}(3: 1)$, and $20 \mathrm{ppm}-380 \mathrm{ppm}(1: 19)$ were achieved at Reynolds number of 62923 in our preliminary single phase water flow experiment. The maximum DR of $64 \%, 73.6 \%, 76 \%, 80 \%$ and $81.6 \%$ for AVM, HPAM, PEO, HPAM-AVM and PEO-AVM respectively were obtained. The results obtained corroborate with the work of Virk[7] and Dingilian \& Ruckenstein [31].

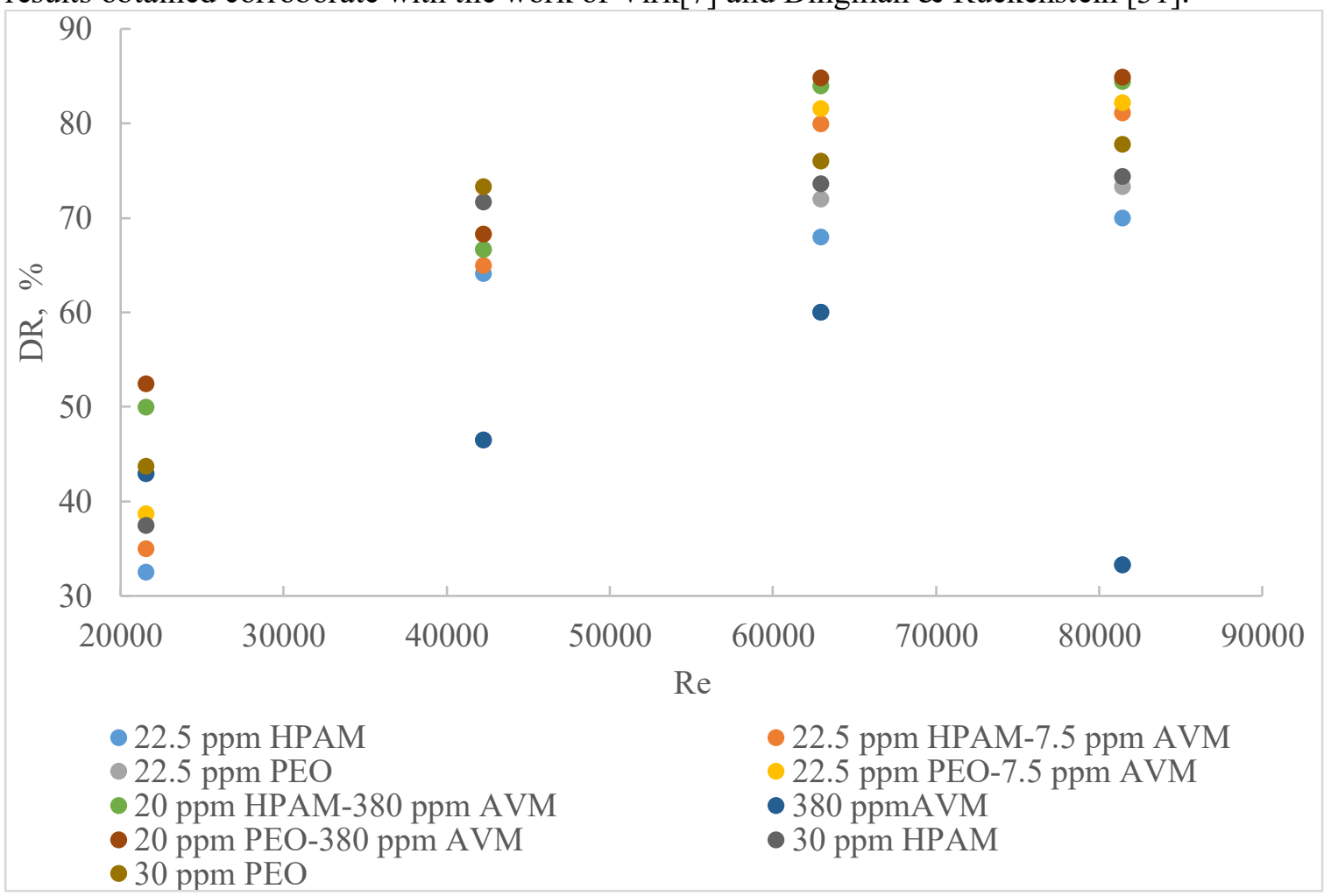

Figure 2. DR vs Reynolds number different at polymers and polymer mixtures concentration in $12 \mathrm{~mm}$ pipe diameter.

\subsection{Effect of Oil İnput Volume Fraction and Mixture Reynolds Number on Drag Reduction}

The drag reduction of HPAM, PEO and AVM as well as their mixtures (HPAM-AVM and PEO-AVM) were studied on oil-water flows (multiphase flow, MPF) at different oil input volume fraction ( $\delta \mathrm{o})$ and mixture Reynolds number (Mix-Re).

Figures 3, 4 and 5 show the results of the effect of oil input volume fractions and mixture Reynolds number (mixture velocity, Umix and superficial velocity, Usw \& Uso) on drag reduction in oil-water flows for HPAM, PEO and AVM. It was observed that drag reduction decreased with increase in oil input volume fraction (from $25 \%-75 \%$ ) due to the increase in superficial velocity of the oil phase (Uso). This result to decrease in the superficial velocity of the water phase as such decreased the Reynolds number of the water phase. Decreased in Reynolds number of the water phase reduce the stretching of the polymer molecules which leads to reduction in drag reduction effectiveness of the drag reducing polymers (DRP) used, the DRPs were only soluble in the water phase [24]. Increase in the Reynolds number of the water phase $\left(\mathrm{Re}_{\mathrm{w}}\right)$ increased the degree of turbulent intensity which enhances the DRP molecules and turbulent eddy interaction, subsequently bringing about increase in DR. This agrees with findings of $[30,24]$.

In addition, no significant drag reduction was observed at $100 \%$ oil input volume which may due to the absence of the water phase Reynolds number $\left(\mathrm{Re}_{\mathrm{w}}=0\right)$ and insolubility of the DRP in the oil phase which corroborate with other findings [30, 18, 17, 24, 8]. Similarly, the drag reduction obtained by PEO solution $\left(65.39 \%\right.$, at $25 \%$ oil input and $\mathrm{Re}_{\mathrm{w}}$ of 47192$)$ was higher than the DR obtained by HPAM and 
Edomwonyi-Otu et al. / Eskişehir Technical Univ. J. of Sci. and Tech. A - Appl. Sci. and Eng. 21 (1) - 2020

AVM solutions $\left(61.54 \% \& 53.85 \%\right.$, at $25 \%$ oil input and $\mathrm{Re}_{\mathrm{w}}$ of 47192$)$ in oil-water flows, which may be attributed to better flexibility of the PEO chain [17].

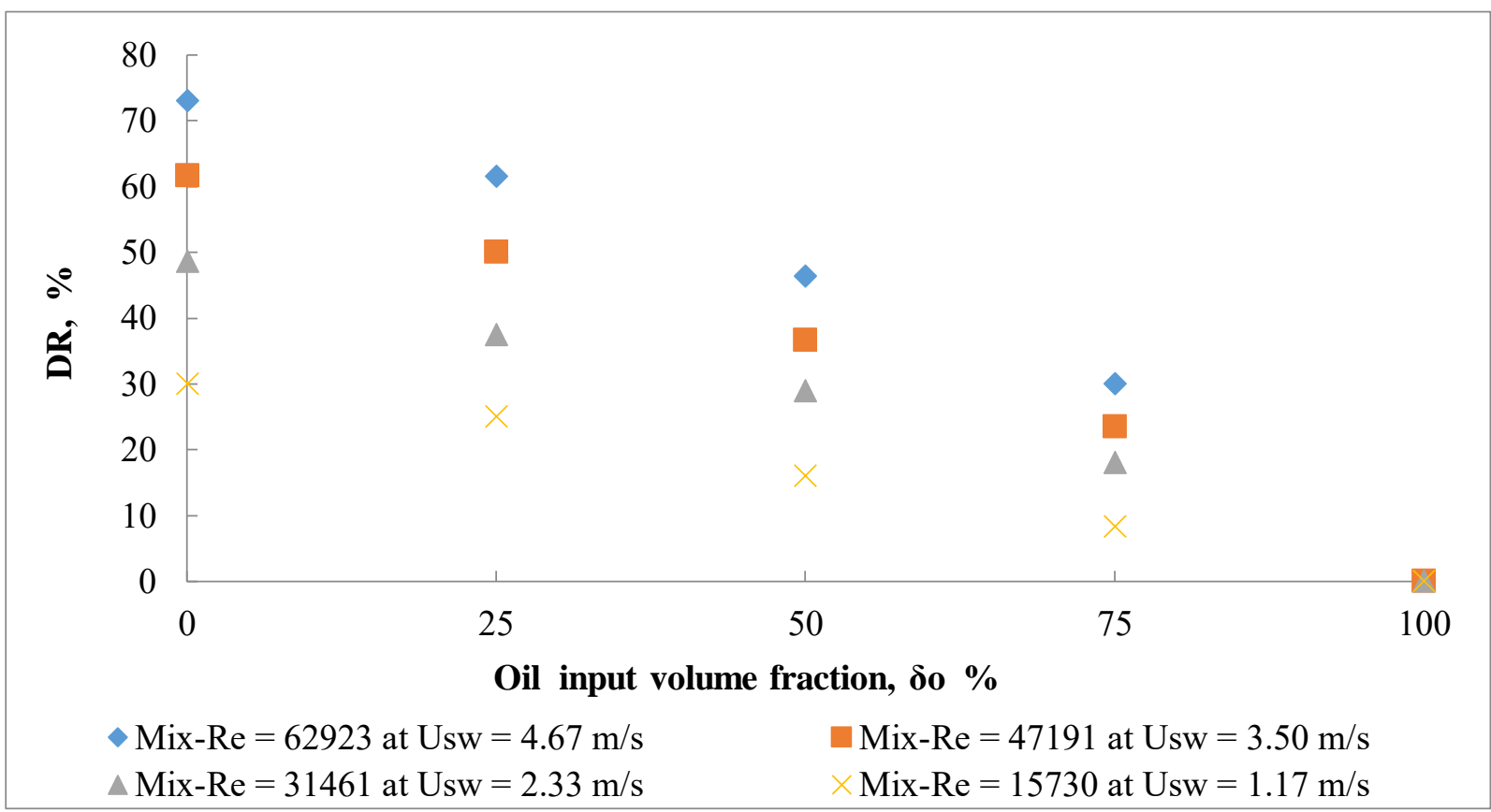

Figure 3. DR vs oil input fraction for HPAM at different mixture Reynolds number (Mix-Re) at concentration of $30 \mathrm{ppm}$ in $12 \mathrm{~mm}$ pipe diameter.

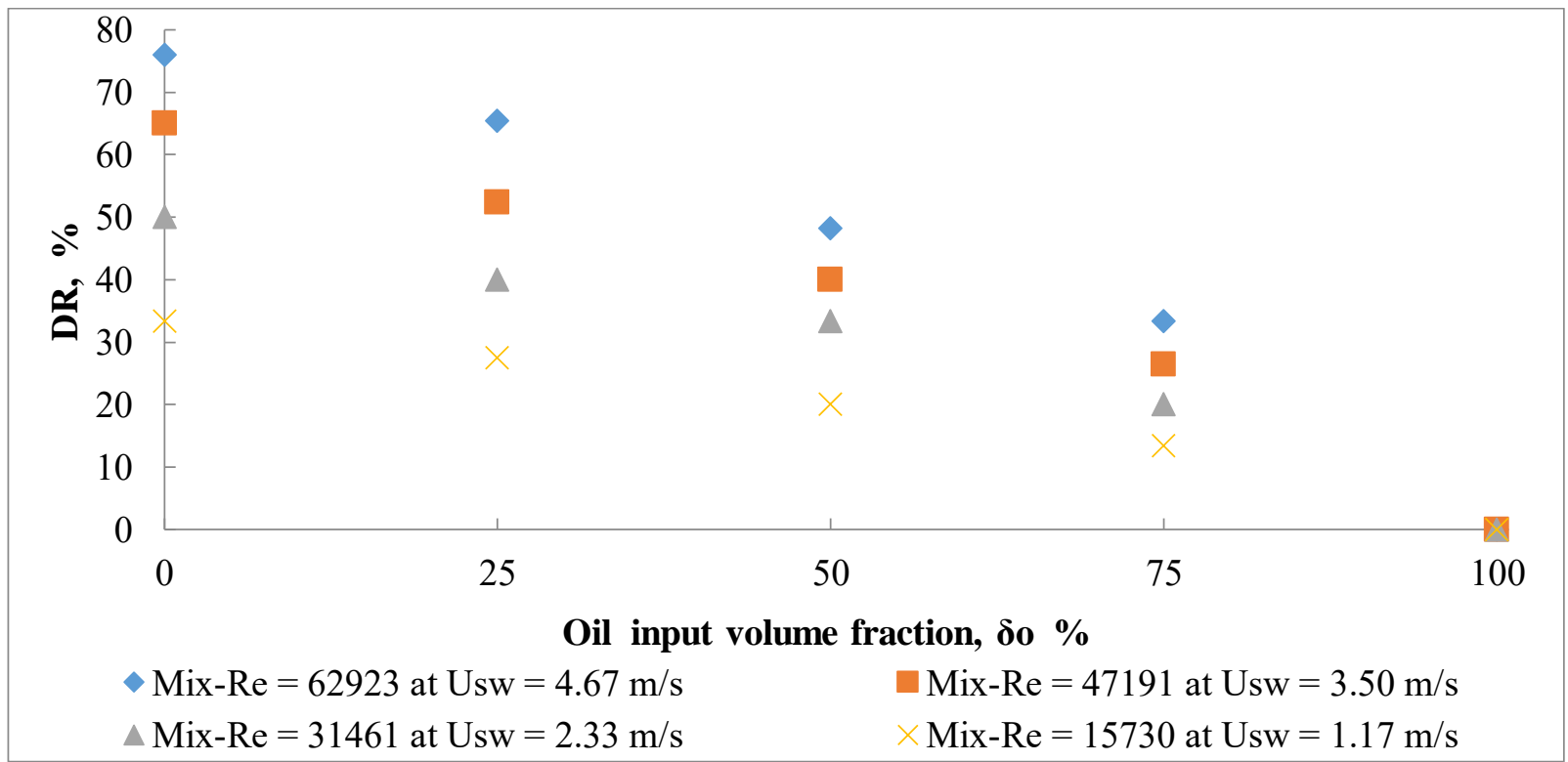

Figure 4. DR vs oil input fraction for PEO at different mixture Reynolds number (Mix-Re) at concentration of 30 ppm in 12 mm pipe diameter. 


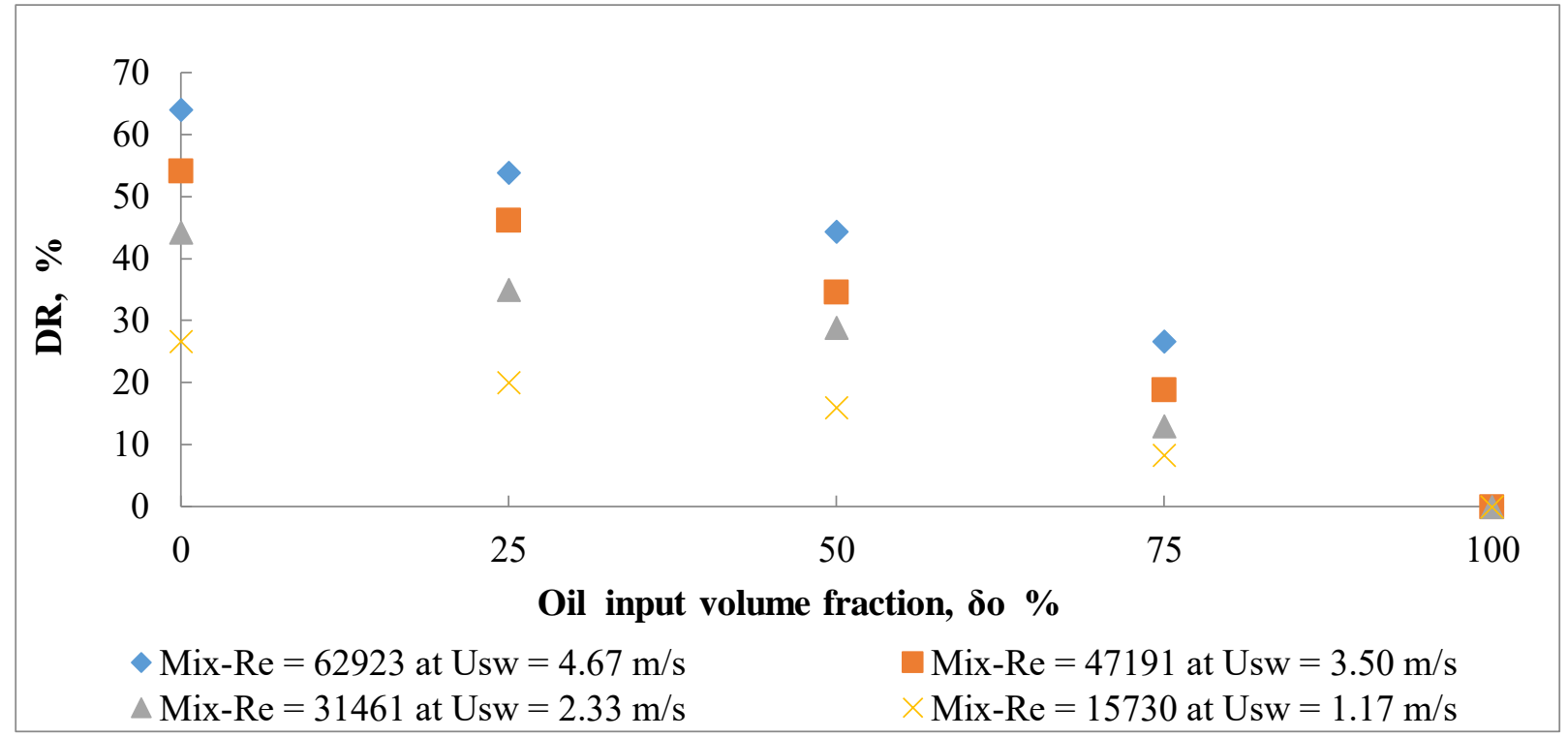

Figure 5. DR vs oil input fraction for AVM at different mixture Reynolds number (Mix-Re) at concentration of $30 \mathrm{ppm}$ in 12 mm pipe diameter.

\subsection{Experiments with Polymer Mixtures}

The DR of two polymer mixtures (HPAM-AVM and PEO-AVM) was studied in oil-water flows at different oil input volume fraction $(\delta o)$ and mixture Reynolds numbers (at different mixture/superficial velocity, Umix, Usw \& Uso). The total concentration (30 ppm \& $400 \mathrm{ppm})$ and mixing ratio (3:1 \& 1:19) were selected from our preliminary work of single phase water flow. Figures $6-13$ show the results of the effect of $\delta$ o and mixture Reynolds number (Mix-Re) on DR in oil-water flow for the polymer mixtures. Similar trend was observed, drag reduction decreased with increase in oil input volume fraction due to decrease in the Reynolds number of water phase for both polymer mixtures.

Furthermore, drag reduction increased with increase in the mixture Reynolds number due to increase in the Reynolds number of the water phase (increase in superficial velocities of water phase), which create more sufficient additive-turbulent eddy interaction, subsequently brings about increased in DR. This corroborate with other findings of $[30,24,8]$.

It was also observed that the DR obtained using polymer mixtures at different $\delta$ o and $\operatorname{Re}_{\mathrm{w}}(65.39 \% \&$ $69.2 \%, 69.3 \% \& 70.77 \%$, at mixing ratio of $3: 1 \& 1: 19,25 \% \delta$ o and $\operatorname{Re}_{\mathrm{w}}$ of 47192 ) was higher than the DR of each of the individual polymer solution alone at the same conditions due to synergistic effect of the polymer mixtures. The synergism in DR in oil-water flows by polymer-polymer mixtures may be due to the interaction amongst the polymer molecules, which influence the extension of the molecules. Also, the synergism in DR may be due to increase in the polymer coil dimension, and their rigidity because coil volume remains most essential properties than molecular weight on DR which is in agreement with the previous works [31,28]. The increase in Reynolds number increased the stretching of polymer molecules which lead the synergy in DR. The DR obtained by PEO mixture $\left(69.3 \%\right.$ \& $70.7 \%$ at $25 \%$ oil input and $\operatorname{Re}_{\mathrm{w}}$ of 47192$)$ was higher than the DR obtained by HPAM mixture $\left(65.39 \%\right.$ \& $69.2 \%$, at $25 \%$ oil input and $\mathrm{Re}_{\mathrm{w}}$ of 47192) in oil-water flows due to better flexibility of the PEO mixture [17]. 
Edomwonyi-Otu et al. / Eskişehir Technical Univ. J. of Sci. and Tech. A - Appl. Sci. and Eng. 21 (1) - 2020

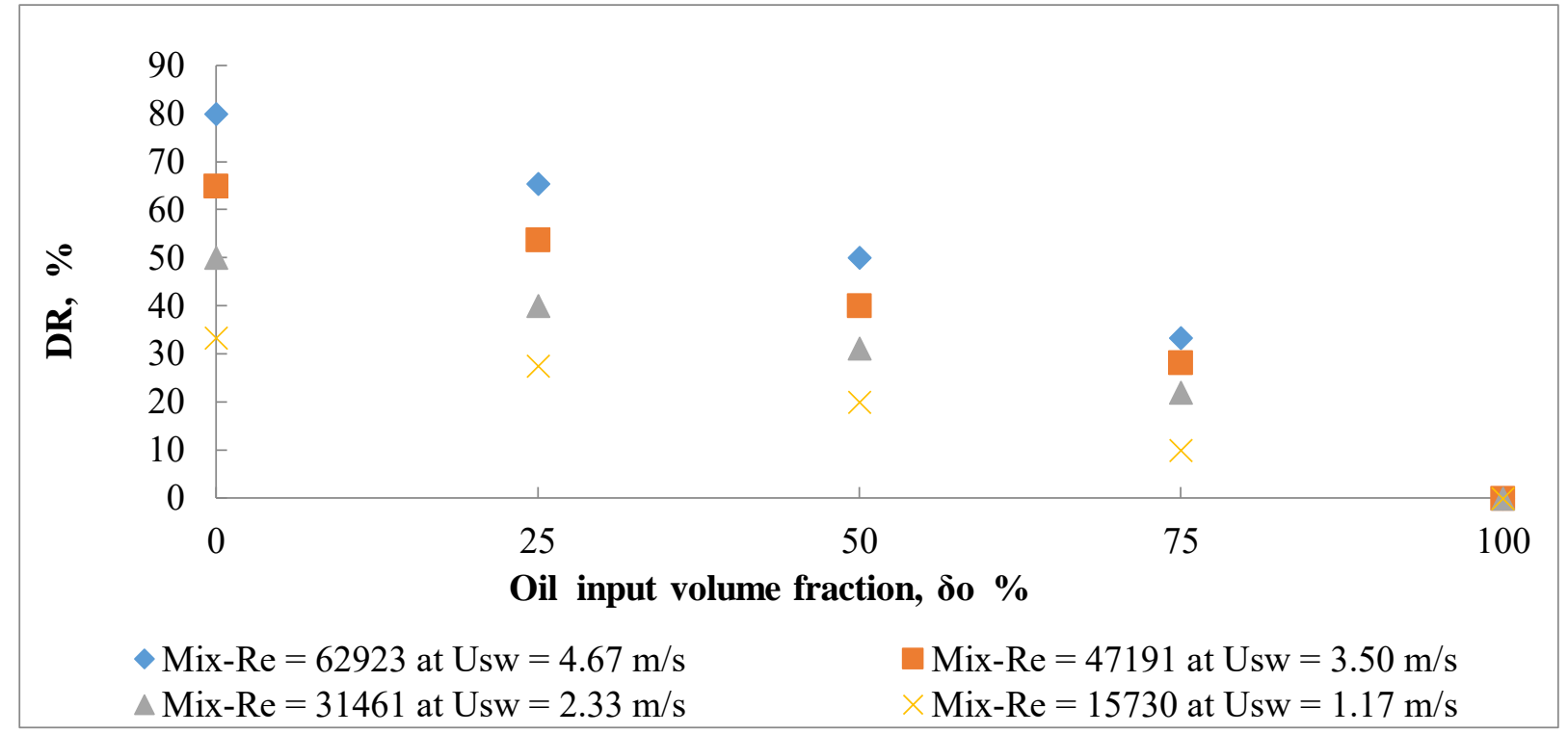

Figure 6. DR vs oil input fraction for HPAM-AVM mixture ratio of 3:1 at different mixture Reynolds number (Mix-Re) and total concentration (TC) of $30 \mathrm{ppm}$ in $12 \mathrm{~mm}$ pipe diameter.

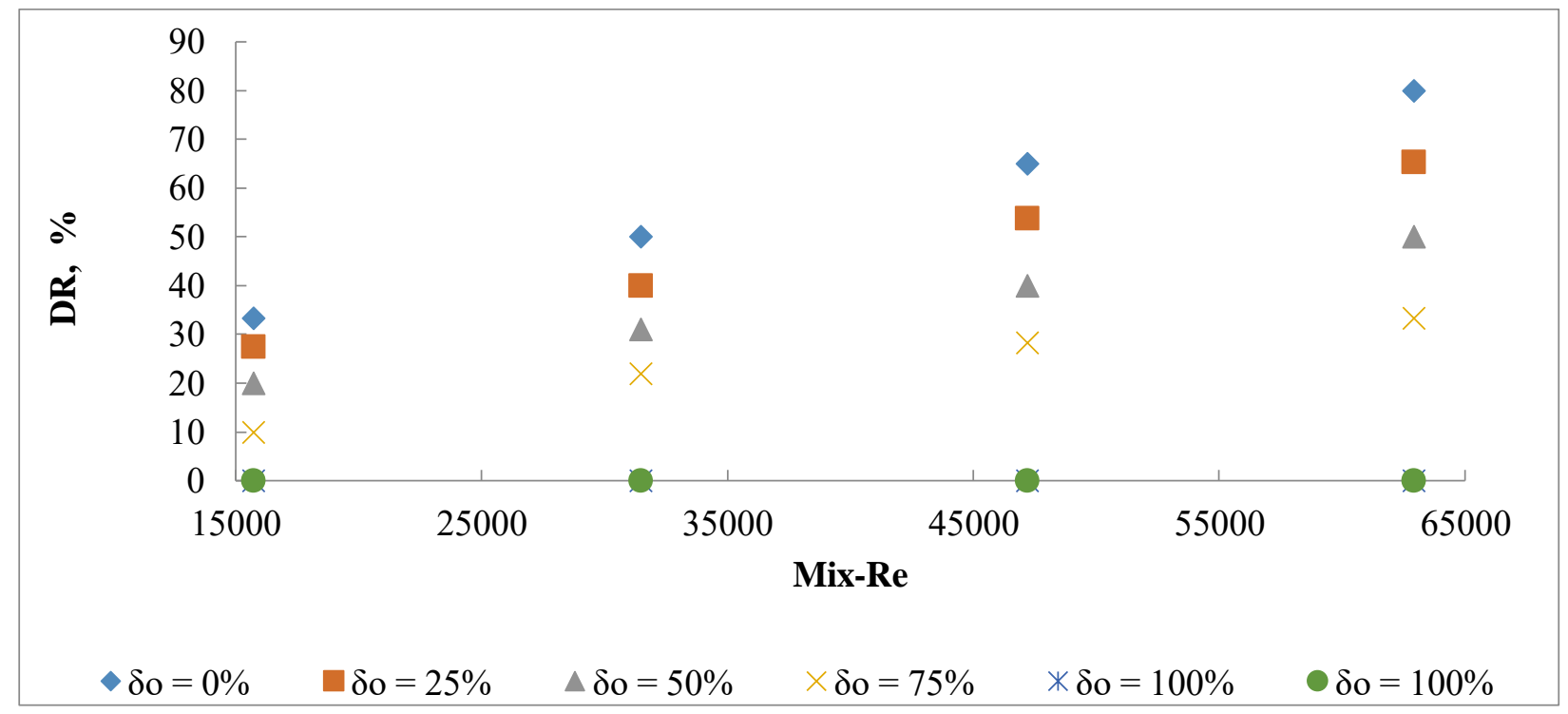

Figure 7. DR vs mixture Reynolds number (Mix-Re) for HPAM-AVM mixture ratio of 3:1 at different oil input volume fraction at total concentration (TC) of $30 \mathrm{ppm}$ in $12 \mathrm{~mm}$ pipe diameter. 
Edomwonyi-Otu et al. / Eskişehir Technical Univ. J. of Sci. and Tech. A - Appl. Sci. and Eng. 21 (1) - 2020

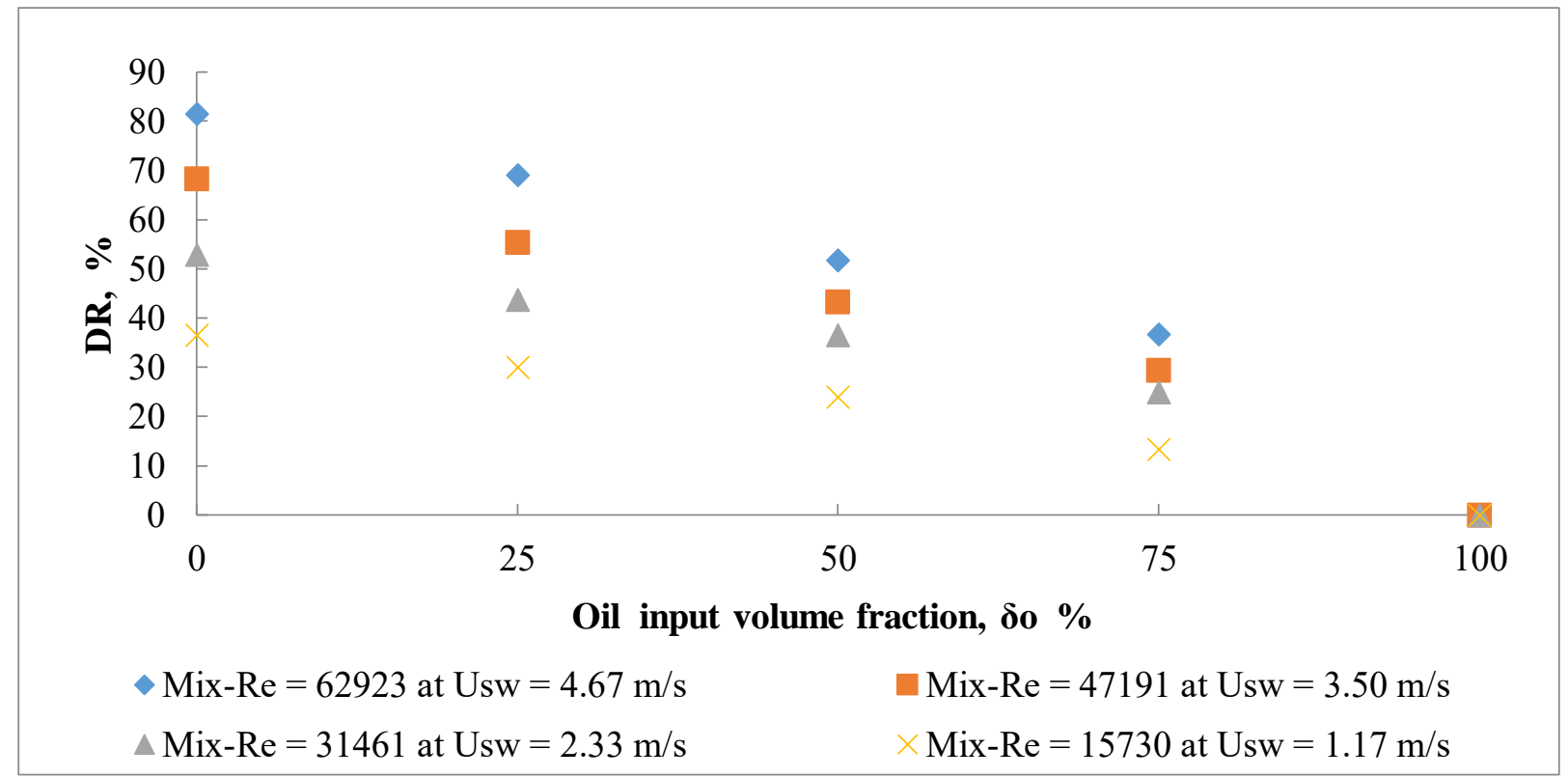

Figure 8: DR vs oil input fraction for PEO-AVM mixture ratio of 3:1 at different mixture Reynolds number (Mix-Re) and total concentration (TC) of $30 \mathrm{ppm}$ in $12 \mathrm{~mm}$ pipe diameter.

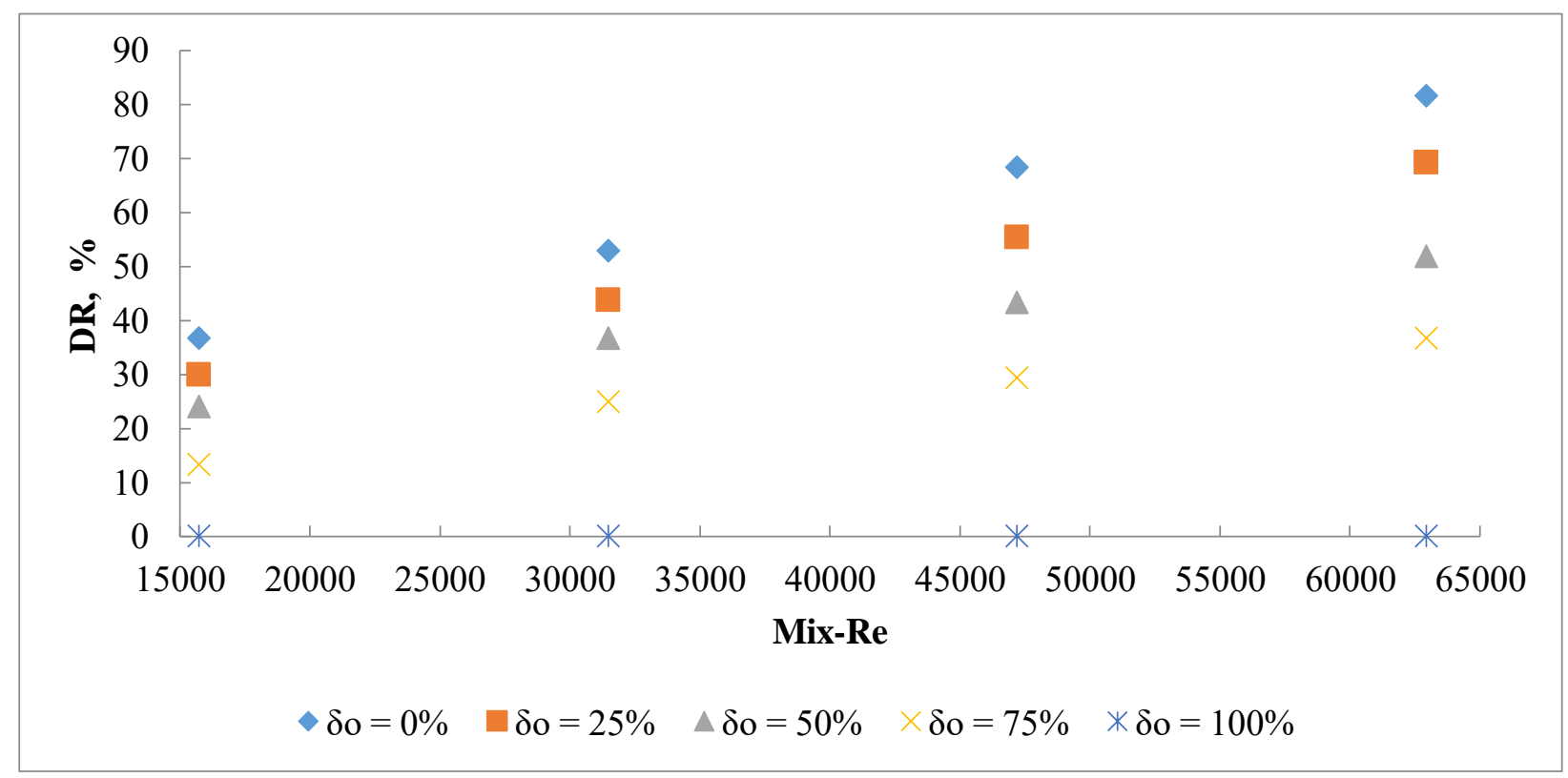

Figure 9. DR vs mixture Reynolds number (Mix-Re) for PEO-AVM mixture ratio of 3:1 at different oil input volume fraction at total concentration (TC) of $30 \mathrm{ppm}$ in $12 \mathrm{~mm}$ pipe diameter. 
Edomwonyi-Otu et al. / Eskişehir Technical Univ. J. of Sci. and Tech. A-Appl. Sci. and Eng. 21 (1)-2020

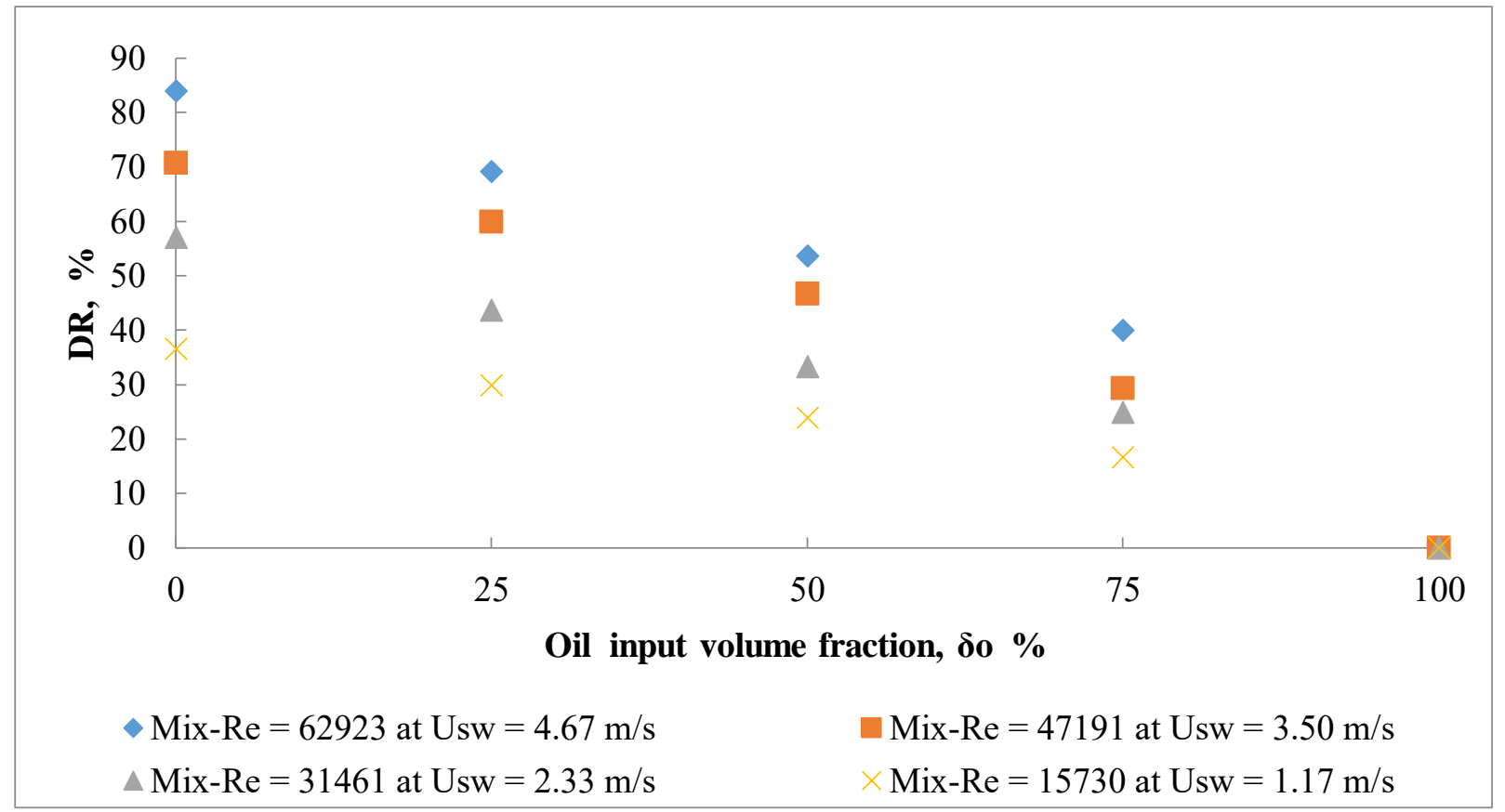

Figure 10. DR vs oil input fraction for HPAM-AVM mixture ratio of 1:19 at different mixture Reynolds number (Re-mix) and total concentration (TC) of $400 \mathrm{ppm}$ in $12 \mathrm{~mm}$ pipe diameter.

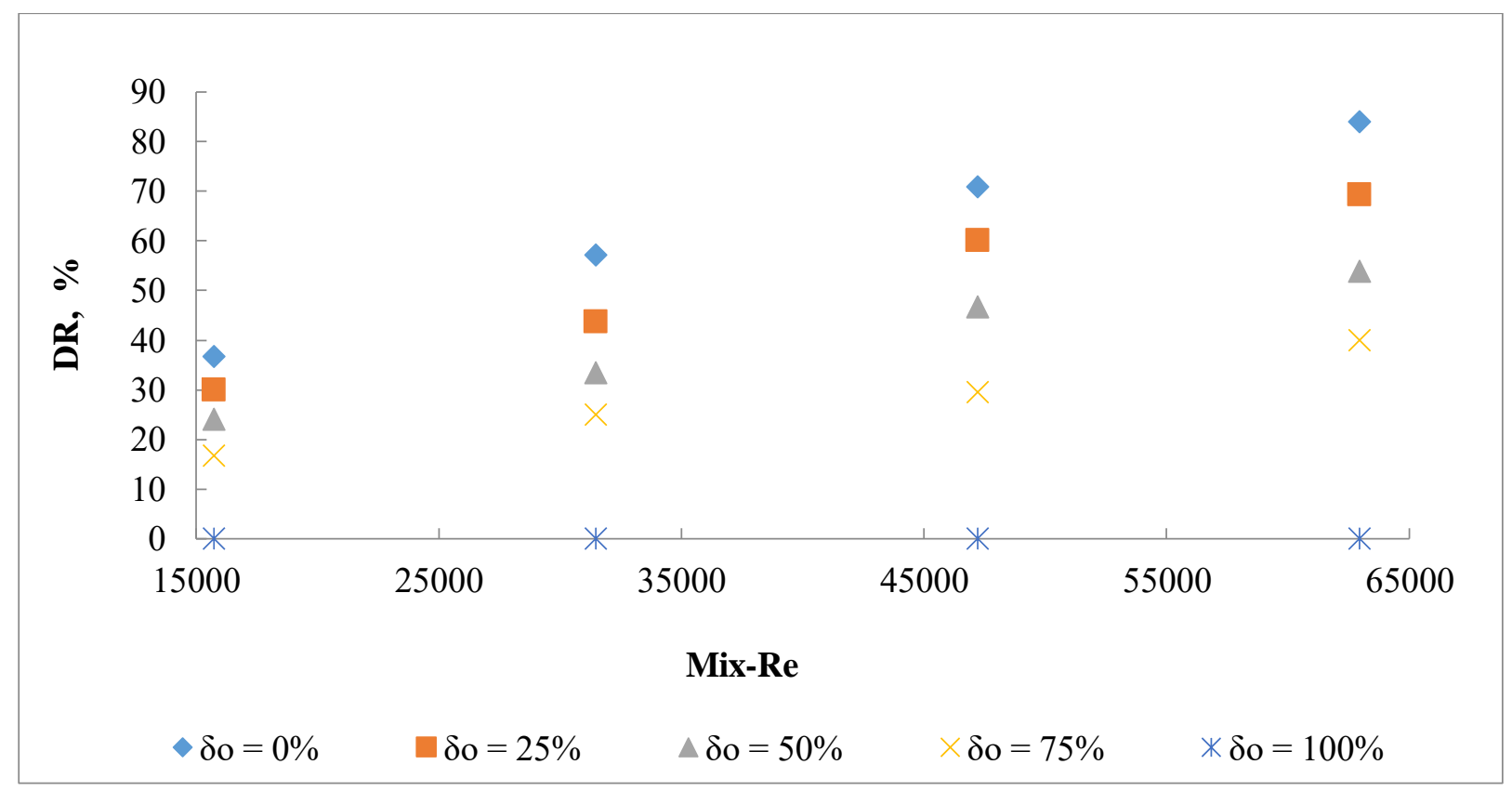

Figure 11. DR vs mixture Reynolds number (Mix-Re) for HPAM-AVM mixture ratio of 1:19 at different oil input volume fraction at total concentration (TC) of $400 \mathrm{ppm}$ in $12 \mathrm{~mm}$ pipe diameter. 


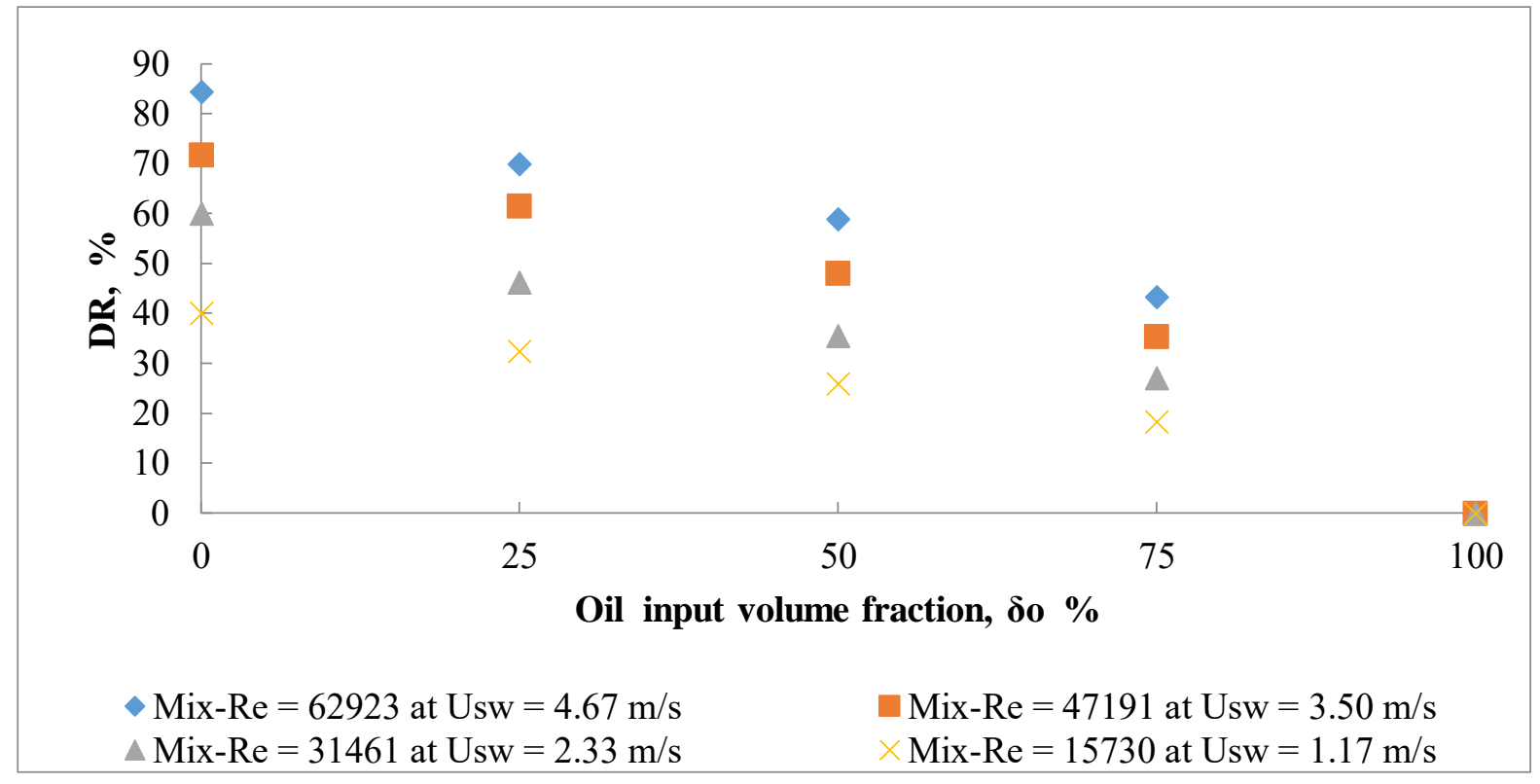

Figure12. DR vs oil input fraction for PEO-AVM mixture ratio of 1:19 at different mixture Reynolds number (Mix-Re) and total concentration (TC) of $400 \mathrm{ppm}$ in $12 \mathrm{~mm}$ pipe diameter.

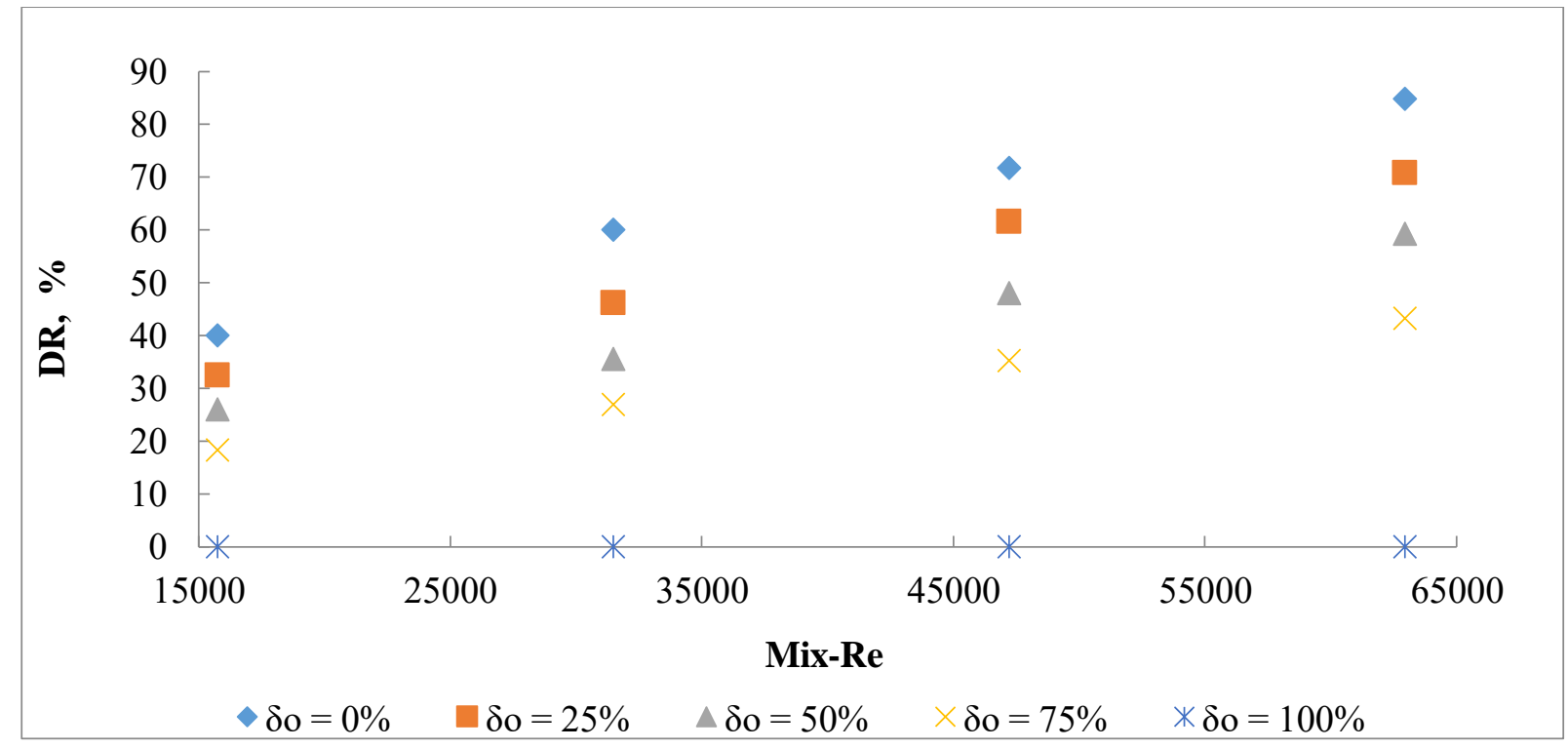

Figure 13. DR vs mixture Reynolds number (Mix-Re) for PEO-AVM mixture ratio of 1:19 at different oil input volume fraction at total concentration (TC) of $400 \mathrm{ppm}$ in $12 \mathrm{~mm}$ pipe diameter.

\section{CONCLUSIONS}

The synergistic effect of natural and synthetic polymers as drag reducing agents on oil-water flow in 12 $\mathrm{mm}$ horizontal pipe diameter at different oil input volume fraction and mixture Reynolds number was investigated. Based on the results obtained, the following conclusions may be drawn:

$>$ Percentage drag reduction obtained in polymer mixture $\{65.39 \%, 69.23 \%$ (HPAM-AVM \& PEO-AVM for mixing ratio of $3: 1$ ) and $69.3 \%$ \& $70.77 \%$ (HPAM-AVM \& PEO-AVM for mixing ratio of 1:19) at oil input of $25 \%$ respectively $\}$ was higher than that of each of the polymer solution alone at the same conditions. 
$>$ Percentage drag reduction decreased with increase in oil input volume fraction and increased with increase in the mixture Reynolds number.

$>$ Also, no DR observed at $100 \%$ oil input volume due the absent of the water phase $\left(\operatorname{Re}_{\mathrm{w}}=0\right)$ and DRP are not soluble in the oil phase.

$>$ Synergism in DR for the polymer mixtures are functions of Re and polymer concentration.

\section{ACKNOWLEDGEMENTS}

The authors would like to thank the members of the multiphase flow and separation systems research group of the Ahmadu Bello University, Zaria, for their moral and technical support.

\section{REFERENCES}

[1] Abubakar A, Al-Wahaibi T, Al-Wahaibi Y, Al-hashmi AR \& Al-Ajmi A. Drag reduction with polymer in oil-water flow in relatively large pipe diameter. International Journal of Advanced and Applied Science. 2016; 2(12): 1-6.

[2] Al-Wahaibi T, Al-Wahaibi Y, Al-Ajmi A, Yusuf N, Al-Hashmi AR, Olawale AS \& Mohammed IA. Experimental investigation on the performance of drag reducing polymers through two pipe diameters in horizontal oil-water flows. Experimental Thermal and Fluid Science. 2013; 50: 139-146.

[3] Edomwonyi-Otu LC \& Angeli P. Effects of Polymer Addition on Pressure Drop and Interfacial Waves in Horizontal Oil-Water Flows. Petroleum Technology Develoment Journal. 2014 July;(2): $41-48$.

[4] Al-Sarkhi A. Drag reduction with polymers in gas-liquid/liquid-liquid flows in pipes: a literature review. Journal of Natural Gas Science and Engineering. 2010; 2: 41-48.

[5] Magit KD, Edomwonyi-Otu LC, Yusuf N, \& Abubakar A. Effect of temperature variation on the effectiveness of partially hydrolyzed polyacrylamide. Research Journal of Engineering and Environmental Sciences (RJEES). 2019; 4(2): 569-577

[6] Ting RY \& Little RC. Characterization of drag reduction and degradation effects in the turbulent pipe flow of dilute polymer solutions. Journal of Applied Polymer Science. 1973; 17(11): 33453356.

[7] Virk PS, Merrill EW, Mickley HS, Smith KA, \& Mollo-Christensen EL. The Toms phenomenon: turbulent pipe flow of dilute polymer solutions. Journal of Fluid Mechanics. 1967; 30(2): 305-328.

[8] Dosumu AI, Edomwonyi-Otu LC, Yusuf N, \& Abubakar A. Guar gum as flow improver in single phase and liquid-liquid flows. Arabian Journal of Science and Engineering (AJSE). 2020. doi.org/10.1007/s13369-020-04429-2

[9] Edomwonyi-Otu LC, Simeoni M, Angeli P \& Campolo M. Synergistic Effect Of Drag Reducing Agents In Pipes of Different Diameters. Nigerian Journal of Engineering. 2016; 22: 1- 5.

[10] Abdulbari HA, Shabirin A \& Abdurrahman HN. Bio-polymers for improving liquid flow in pipelines. Journal of Industrial and Engineering Chemistry. 2014; 20(4): 1157-1170.

[11] Brostow, W. Drag reduction in flow: Review of applications, mechanism and prediction. Journal of Industrial and Engineering Chemistry. 2008; 14(4): 409 - 416.

[12] Marmy RMS, Hayder AB and Rosli MY. Improving the flow in pipelines by Cocos nucifera fiber waste. International Journal of Physical Science. 2012; 7(26): 4073-4080. 
[13] Edomwonyi-Otu LC\&Adelakun DO. Effect of Heavy Molecular Weight Polymer on Quality of [14] Drinking Water. Materials Today Communications. Elsevier Publication. 2018; 15: 337-343.

[15] Deshmukh SR \& Singh RP. Drag reduction characteristics of graft copolymers of xanthan gum and polyacrylamide. Journal of Applied Polymer Science. 1986; 32: 6163-6176.

[16] Singh RP. Advanced Turbulent Drag Reducing and Flocculating Materials Based on Polysaccharides. Polymers and Other Advanced Materials. 1995; 75: 227-249.

[17] Nour AH, Nuraffini K \& Hayder AS. Grafted Natural Polymer as New Drag Reducing Agent : An Experemental Approach. Chemical Industry and Chemical Engineering Quarterly. 2012; 18(3): 361-371.

[18] Al-Wahaibi T, Smith M \& Angeli P. Effect of drag-reducing polymers on horizontal oil-water flows. Journal of Petroleum Science and Engineering. 2007; 57(3-4): 334-346.

[19] Al-Yaari M, Soleimani A, Abu-Sharkh B, Al-Mubaiyedh U \& Al-Sarkhi A. Effect of drag reducing polymers on oil-water flow in a horizontal pipe. International Journal of Multiphase Flow. 2009; 35: 516-524.

[20] Omer A, Pal R. Pipeline flow behavior of water-in-oil emulsions with and without a polymeric additive. Chemical Engineering Technology. 2010; 33(6): 983-992.

[21] Yusuf N, Al-Wahaibi T, Al-Wahaibi Y, Al-Ajmi A, Al-Hahmi AR, Olawale AS. Mohammed IA. Experimental study on the effect of drag reducing polymer on flow patterns and drag reduction in a horizontal oil-water flow. International Journal of Heat and Fluid Flow. 2012; 37: 74-80.

[22] Langsholt M. An Experimental Study on Polymeric Type DRA used in Single- and Multiphase Flow with Emphasis on Degradation, Diameter Scaling and the Effects in Three-phase Oil-WaterGas Flow. Institute for Energy Technology (IFE), Norway, 2012.

[23] Edomwonyi-Otu LC. Distortion of velocity profiles of water flow with heavy molecular weight polymers. Transfer Phenomenon in Fluid and Heat Flows VII in Journal of Defect and Diffusion Forum (DDF). Trans Tech Publications, Switzerland. 2019; 392: 228-238

[24] Edomwonyi-Otu LC, Chinaud M \& Angeli P. Effect of drag reducing polymer on horizontal liquidliquid flows. Experimental Tharmal and Fluid Science. 2015; 1-27.

[25 Bari HAA, Letchmanan K \& Mohd YR. Drag Reduction Characteristics Using Aloe Vera Natural Mucilage: An Experimental Study. Journal of Applied Science. 2011; 11(6): 1039-1043.

[26] Bozzi A, Perrin C, Austin S. Quality and Authenticity of Commercial Aloe Vera Gel Power. Food Chemistry. 2007; 103: 22-30.

[27] Davis RH. Aloe Vera-A Scientific, Approach. Vantage Press Inc., New-York, USA: 1997. pp. 290306.

[28] Reddy GV \& Singh RP. Drag reduction effectiveness and shear stability of polymer-polymer and polymer-fibre mixtures in recirculatory turbulent flow of water. Rheologica Acta. 1985; 24: 296311

[29] Malhotra JP, Chaturvedi PN, \& Singh RP. Drag Reduction by Polymer-Polymer Mixtures. Journal of Applied Polymer Science. 1988; 36: 837-858. 
Edomwonyi-Otu et al. / Eskişsehir Technical Univ. J. of Sci. and Tech. A-Appl. Sci. and Eng. 21 (1) - 2020

[30] Edomwonyi-Otu LC \& Angeli P. Separated Oil-Water Flows With Drag Reducing Polymers. Experimental Thermal and Fluid Science Journal. 2019; 102: 467-478

[31] Dingilian G \& Ruckenstein E. Positive and Negative Deviations from Additivity in Drag Reduction of Binary Dilute Polymer Solutions. AlChE Journal. 1974; 20(6): 1222-1224. 